\title{
Um olhar teórico-pedagógico sobre a leitura
}

\author{
Bruno de Andrade Rodrigues
}

Faculdade Paraíso (FAP)

\begin{abstract}
Resumo
Neste artigo, nosso interesse repousa na consideração do ensino de leitura que se oriente pelo objetivo de formar leitores capazes de alcançar as camadas de significação subjacentes à superfície textual. Insistimos na necessidade de o professor de português não só exibir uma sólida formação no que toca, mormente, ao domínio do arcabouço teórico-metodológico de que nos dão testemunho a Linguística Textual e a Análise do Discurso, como também de conduzir sua prática pedagógica de modo a desconstruir certas crenças e ideias ainda muito arraigadas na consciência dos aprendizes, relativamente à experiência de leitura escolar.
\end{abstract}

Palavras-chave: texto, discurso, sujeito, sentido, coerência

\begin{abstract}
This article considers the teaching of reading when its objective is to develop readers' ability to reach layers of meanings that are beneath the surface of the text. I argue that Portuguese teachers not only need to show solid knowledge and background of theory and methods based on text linguistics and discourse analysis, but also need to conduct their teaching practice in such a way as to deconstruct fixed beliefs and ideas that learners hold concerning the experience of reading at school.
\end{abstract}

Key words: text, discourse, subject, meaning, coherence

\section{INTRODUÇÃO}

Um dos desafios pedagógicos que o professor de português como língua materna tem de enfrentar, seja no nível escolar (nas séries mais avançadas do ensino fundamental e no ensino médio), seja no nível superior de ensino, é desenvolver práticas de leitura que assentem no princípio teórico de que ler não se confunde com uma atividade durante a qual se vai 'pinçando' significados que estão, por assim dizer, boiando na superfície textual. Em outras palavras, ao empreender práticas de leitura, o professor deve esforçar-se por demonstrar aos aprendizes que a leitura não consiste num processo de decodificação linear das palavras e expressões textuais, com vistas a apreender significados que estão localizados no material linguístico de que é feito a superfície textual. Aqui, são pertinentes as palavras de Ingedore Koch (2004:159), que, 
ao se referir à competência que os alunos devem adquirir e desenvolver, pela mediação do professor, escreve:

(...) nas aulas de leitura, é importante conscientizar o aprendiz da existência, em cada texto, de diversos níveis de significação. Isto é, cumpre mostrar-lhe que, além da significação explícita, existe toda uma gama de significações implícitas, muito mais sutis, diretamente ligadas à intencionalidade do produtor.

Resumidamente, o que se espera do leitor experiente é que ele seja capaz de apreender a significação profunda do texto. Para tanto, a leitura operada deve semelharse a uma escavação - não no sentido de busca de significados soterrados - mas no sentido de reconstrução dos mecanismos textuais-discursivos responsáveis pela produção do texto ${ }^{1}$. Assim é que compreender um texto depende da capacidade de o leitor, durante a leitura, entender o funcionamento e a estrutura do texto; apreender os mecanismos e estratégias responsáveis pela existência funcional do texto.

É comum a crença entre os alunos - crença que se expressa sob forma de queixas e questionamentos - de que ler um texto é ser capaz de entender o que o autor diz explicitamente. Dão testemunho disso algumas respostas de nossos alunos aos questionários de interpretação, nos exercícios e provas. Tais respostas, não raro, iniciam-se com expressões como "segundo o autor...", "o autor diz que", "como o próprio autor fala...”, etc. Além de acreditar que a leitura se dá num nível explícito e literal, clara está a crença, consciente ou não, na onisciência e soberania do autor. Não vamos, no entanto, discorrer sobre essa matéria. As teorias do discurso legam-nos preciosos ensinamentos sobre a questão do sujeito e as diferentes funções enunciativas que cumpre no discurso.

Em primeiro lugar, a fim de mostrar ao aluno que aquela crença é insuficiente para a compreensão de um texto, o professor deve apontar o fato de que o autor, ao produzir um texto, o faz operando com diversos níveis de implícito, conscientemente ou não. Aliás, convém lembrar-lhes que muitos dos sentidos não são previstos pelo autor. Em segundo lugar, vale discutir com eles o papel social do autor, como a instância discursiva responsável pela unidade e coerência do discurso; nesse tocante, impõe-se

\footnotetext{
${ }^{1}$ Entendemos por "reconstrução" o movimento cognitivo, para o qual intervêm diversas competências (lingüística, cognitiva, interacional, etc.), oposto ao operado pelo produtor do texto, que deve ser feito pelo leitor, com vistas a apreender as intenções, os objetivos, os propósitos, as crenças, as ideologias, as diversas representações do sujeito, etc. Essa "reconstrução", que representa o processo de compreensão do texto pelo leitor, depende de um trabalho de "desconstrução" do texto, a saber, enquanto o autor vai das intenções ao texto, o leitor faz o movimento contrário - vai do texto às intenções. A "desconstrução" se dá no processo de interpretação.
} 
mostrar ao aluno que o autor é uma das funções assumidas pelo locutor (o produtor do texto).

Outra crença comum entre os estudantes é a que afeta a arbitrariedade como elemento decisivo da interpretação. Aqui, impõe-se outra discussão com os alunos. Claro é que a interpretação não pode ser abandonada à arbitrariedade de um "sujeitoleitor" onipotente (na verdade, também o leitor é afetado pela ideologia). Na interpretação de um texto, intervêm a história de leituras do texto e a história de leituras do leitor. Esse leitor não deve ser considerado um indivíduo empírico, mas um sujeito social, que encerra um acervo de conhecimentos vários, adquiridos ao longo de suas experiências de mundo. Esse acervo é mobilizado durante o processo de leitura e é responsável pelas diferentes leituras que cada leitor pode fazer. Isso explica a surpresa, ou mesmo desconforto do aluno, em face do fato de o seu professor ter "visto" coisas no texto que ele, aluno, não conseguiu "ver". O leitor, em suma, é um sujeito situado sóciohistoricamente.

No que toca à referida crença discente, o professor tem de tomar cuidado para não impor aos alunos nem a sua leitura nem a de uma autoridade outra (como a do crítico). É interessante observar que, ao sugerir a arbitrariedade como elemento decisivo na compreensão de um texto, o aluno questiona o lugar social do professor. É comum ouvir os alunos dizerem coisas como "então, a gente tem que interpretar como o senhor [professor] quer?”, “a gente tem que acomodar a nossa interpretação à que o senhor fez", etc, depois de verificarem seu insucesso nos exercícios de interpretação textual, por exemplo.

Visando a contribuir para que a crença na arbitrariedade como elemento decisivo na compreensão do texto seja extirpada, o professor deve anunciar uma idéia basilar, colhida dos estudos da Análise do Discurso, segundo a qual todo texto admite muitos sentidos (embora nem todos). Não há, assim, dirá o professor, um único sentido para um texto, mas muitos sentidos possíveis ${ }^{2}$. No entanto, tais sentidos não derivam da arbitrariedade do leitor; mas são tributários da capacidade de o leitor transitar entre as

\footnotetext{
2 Os sentidos de um texto são produzidos na interação do sujeito-leitor com as diferentes formas-sujeito, sob as quais se representa o autor, no discurso. Os sentidos se revestem de uma concretude histórica. Os sentidos não estão no texto, mas são produzidos a partir dele, na sua relação com a História.
} 
diversas formações discursivas ${ }^{3}$ que atravessam o texto.

O que o aluno, em geral, não percebe é que a sua leitura não está "errada"; mas pode ser insatisfatória, tendo em conta certas circunstâncias pedagógicas. O leitor comum assume a transparência da linguagem no momento em que se põe a interpretar um texto; o leitor experiente parece intuir sua opacidade, o que lhe permite "capturar" as palavras que estão por detrás das palavras imediatamente acessíveis.

Não vamo-nos ocupar na discussão dos limites das possibilidades de leitura para um texto. Não obstante, vale referir as palavras de Orlandi (2008:114), que avaliando a relação entre texto e leitura, escreve:

Todo texto em relação à leitura teria, pois, vários pontos de entrada e vários pontos de fuga. Os pontos de entrada são as diferentes perspectivas de posições de sujeito. Os pontos de fuga são as diferentes perspectivas de atribuição de sentidos: ao relacionar-se com os vários pontos de entrada, o leitor pode produzir leituras que encaminham-se em várias direções. Não necessariamente previstas, nem organizadas, nem passíveis de cálculo. Há várias perspectivas de leituras. Há diferentes posições do sujeito-leitor.

Sem descer a pormenores, do excerto de Orlandi pode-se depreender, por um lado, que o universo discursivo parece "filtrar" certas leituras, excluindo outras; por outro lado, tendo em conta a avaliação da questão das leituras possíveis, não parece importar tanto a tentativa de determinação do que é possível ler e do que não é possível, na medida em que o leitor sempre procurará realizar uma leitura minimamente coerente para um texto. O que importa é reconhecer que o leitor pode fazer uma leitura superficial e, portanto, pouco satisfatória tendo em conta as possibilidades de leitura previstas pelo texto. Ciente disso, o professor deve patentear aos alunos, nas atividades com o texto, em sala de aula, como o texto se estrutura e funciona; deve mostrar a eles como se organizam e operam os mecanismos textuais-discursivos (operadores argumentativos, polifonia, pressuposição, intertextualidade, etc.).

Uma das dificuldades observadas, nas atividades de interpretação textual, é a dificuldade que muitos alunos têm de apoiar a interpretação no material linguístico. Em outras palavras, muitos alunos têm dificuldade de reconhecer expressões que estabelecem determinados tipos de relações semântico-discursivas, ou de, a partir de

\footnotetext{
3 A importância do conceito de formação discursiva estriba-se na consciência da heterogeneidade constitutiva do discurso e do sujeito. Toda formação discursiva encerra formações ideológicas, nas quais se inscreve o sujeito, que é sempre plural. A noção de formação discursiva implica a consciência de que todo discurso é aberto para a exterioridade, já que se relaciona a outros discursos e à História que os engendra.
} 
uma dada conclusão, reconhecer a expressão linguística que a encaminha, etc. Conscientizá-los de que as expressões linguísticas servem de "pistas" para a produção do sentido e demonstrar-lhes, por meio do testemunho textual, a validade desse princípio teórico constitui um ensinamento importante para a formação de leitores mais experientes, capazes, portanto, de investir cognitivamente nos diversos níveis de significação do texto.

\section{UMA AMOSTRA DE TRABALHO}

\section{A representação do sujeito}

O texto sobre o qual nos vamos debruçar é um artigo de Rubem Alves, educador, filósofo, teólogo e escritor brasileiro, intitulado de As mãos perguntam, a cabeça pensa, publicado em 21 de julho de 2002, no jornal Folha de São Paulo. O texto se acha na seção Anexos.

Todo texto é uma entidade heterogênea; portanto, não se pode pretender dar conta de todos os aspectos já considerados pelos estudos que se ocupam dele. Temos de operar, inevitavelmente, alguns recortes. Como cuidamos que a questão da representação do sujeito é fundamental para pôr em xeque a soberania do autor e, consequentemente, para dar a saber ao aluno que o autor é uma instância do discurso e que esse autor se representa a partir de perspectivas diversas no texto, consideraremos a perspectiva polifônica.

O sujeito instala um "eu" no discurso, como se depreende do seguinte excerto:

"Encaro com maior desconfiança os laboratórios nas escolas. Acho que sua função, nas escolas, não é ensinar ciência aos estudantes, mas impressionar os pais (...)”.

A esse "eu" responsável pelo discurso chamaremos de "locutor". Esse locutor instaura um alocutário (o "tu" a que se destina o discurso), marcado pela expressão "vocês". Com a instauração desse alocutário, marcado por "vocês", fica evidente a função interacional própria de todo texto.

"Vocês se lembram do que escrevi sobre os moluscos, que, para sobreviver, constroem conchas eficazes e belas?" 
Quem são esses "vocês" a que se dirige o locutor? Considerando que o texto foi publicado num jornal de grande circulação no país, o "vocês" se referem aos leitores em potencial, que se supõe acompanham as publicações do autor.

Escusando-nos, desde já, de uma possível consideração descurada do aspecto polifônico do texto, distinguimos, de imediato, duas perspectivas sob as quais se representa o locutor. Uma que diz respeito à perspectiva de um filósofo-cientista, a que atribuiremos a notação $\mathrm{E}_{1}$ (enunciador 1); outra que toca à perspectiva de um educador $\left(E_{2}\right)$. As duas perspectivas, na verdade, parecem se confundir. Decerto, as duas perspectivas são concordantes; não há tensão entre elas, mas aderência. Há que reconhecer também outra "voz", a do senso-comum, representado pelos "pais".

“(...) Os pais se impressionam facilmente. Vendo os laboratórios, eles concluem: "Uma escola com um laboratório moderno assim deve ser uma boa escola".

Destacamos a ocorrência de "uma escola com um laboratório moderno...", no primeiro excerto citado, pela qual o $\mathrm{E}_{1}$ simula uma enunciação comum (discurso) de que são protagonistas os pais dos alunos. Fique claro, pois, que a "voz" dos pais ecoa no texto.

Os enunciadores $E_{1}$ e $E_{2}$ procuram calar a "voz" do $E_{3}$ (pais); procuram invalidar a perspectiva desse enunciador. O locutor, representado nos enunciadores 1 e 2, também trava diálogo com um enunciador $4\left(\mathrm{E}_{4}\right)$, representado por "pessoas que são capazes de produzir pesquisas nos laboratórios, mas que, andando em meio aos objetos e situações de seu cotidiano, vêem e pensam como se nada soubessem da ciência". Também a perspectiva desses enunciadores deve ser refutada.

A perspectiva do enunciador-educador é patente no seguinte excerto:

"Pensei, então, numa escola que fosse uma casa comum, dessas onde os alunos moram, parecida com o espaço de sua vida real”.

Estamos conscientes de que a consideração das diversas formas-sujeito implica o reconhecimento das formações discursivas nas quais o sujeito se movimenta. A formação discursiva é o lugar da constituição do sentido e do sujeito; este se identifica situando-se numa determinada formação discursiva. Contudo, não pretendemos aqui apresentar uma análise exaustiva; ademais, não se pretende aqui propor que se ensine 
aos aprendizes conceitos como "formação discursiva" e "formação ideológica". Não se pretende propor que se deve transferir noções teóricas diretamente para a realidade pedagógica.

Finalmente, há que reconhecer que o locutor assume uma perspectiva com que se identifica com todos os homens. Trata-se de um $\mathrm{E}_{5}$ que se confunde com o próprio locutor, como se nota no fragmento abaixo:

"Pensamos para ajudar as mãos. Das mãos nascem as perguntas. Da cabeça nascem as respostas."

Note-se que o locutor atualiza um "nós", que se refere aos seres humanos, às pessoas em geral. Aqui o locutor se identifica, de certo modo, com os enunciadores $E_{3}$ e $\mathrm{E}_{4}$, já que se inclui na classe dos seres humanos, das pessoas em geral: "todos nós pensamos para ajudar as mãos".

Finalmente, gostaríamos de ressaltar a ocorrência de discurso indireto, no seguinte excerto:

"Li uma entrevista do Amyr Klink em que, indagado sobre a educação dos filhos, disse que gostaria que seus filhos aprendessem como aprendem as crianças numa ilha (...)" (grifo nosso)

O discurso indireto sinaliza a presença de outro locutor, de outra "voz", a saber, a de Amyr Klink. Note-se que o locutor 1 incorpora à sua fala a fala de outro locutor. $\mathrm{O}$ locutor 1, responsável pela enunciação, faz uma espécie de tradução (paráfrase), já que usa suas próprias palavras para materializar a enunciação de outro locutor (no caso, Amyr Klink). Escusa dizer que as duas vozes em tela são concordantes.

A análise, decerto, não se encerra aqui; no entanto, limitamo-nos a essas considerações acerca da representação do sujeito.

\section{CONCLUSÃO}

A despeito das lacunas deste trabalho, esperamos que nossa reflexão tenha contribuído para despertar no professor a consciência da necessidade de se empreender trabalhos de leitura em que se busque explicitar aos alunos os mecanismos de construção textual. É mister que o professor leve os alunos à compreensão desses 
mecanismos e das estratégias argumentativas de que lança mão o autor para produzir um texto. Acreditamos, assim, que a prática pedagógica atenderá aos seguintes objetivos:

1) levar os aprendizes a entender que o texto é dotado de uma tessitura, é uma teia de relações, e não um amontoado de palavras e frases;

2) levar os alunos a compreender como um texto se organiza, se estrutura e cumpre determinadas funções sócio-comunicativas;

3) contribuir para a potencialização da capacidade discente de interpretação e compreensão de texto.

Os objetivos a serem atingidos não se resumem a esses três, evidentemente; há outros mais que podem ser satisfeitos. O que propomos é que se mostre ao aluno como se pode chegar a determinadas conclusões, como são possíveis determinadas leituras, tendo em conta o universo textual, para cuja compreensão é necessária a mobilização de um vasto e variado conjunto de saberes arquivados na memória do leitor. A tarefa do professor deverá ser orientada de modo que o aluno não mais acredite que interpretar é um mistério, é um "dom" dado a alguns "iluminados". A habilidade de leitura (subentenda-se “de interpretação textual”) pode ser desenvolvida. É possível, pois, ensinar a ler.

Se, por um lado, o ato de interpretar se faz na base do material linguístico com que se constrói o texto; por outro lado, vai mais além, ou seja, uma interpretação é tanto mais bem-sucedida quanto mais eficiente for a capacidade de o leitor recuperar os implícitos e os outros textos com que o texto, objeto de leitura, se relaciona, ativar os conhecimentos necessários para a compreensão, compreender como se dinamizam as "vozes" que povoam o texto; enfim, apreender uma gama variada de elementos que, muita vez, não são diretamente observáveis, quer porque não estejam explícitos, como certas informações e relações que devem ser feitas por inferenciação, quer porque se confundem num mesmo recorte enunciativo ou estão mascarados, como sucede com certas "vozes" no discurso.

Não se pode esquecer também que a compreensão de um texto torna-se tanto mais plena quanto mais satisfatória é a competência do leitor em reconhecer os silenciamentos e as ideologias (ou formações ideológicas) com que o sujeito está comprometido e às quais se devem as suas representações da realidade. Nesse tocante, cumpre notar que as ideologias que atravessam o discurso estão sempre a serviço de 
interesses das classes dominantes numa dada formação social. Elas são, por natureza, hegemônicas, na medida em que, necessariamente, servem para estabelecer e sustentar relações de dominação; portanto, reproduzem uma determinada ordem social que favorece certos grupos dominantes.

Finalmente, para que se empreenda um trabalho de leitura que vise à formação de leitores cada vez mais experientes, mais críticos, mais competentes, é indispensável ao professor a familiarização e domínio das contribuições legadas pela Linguística Textual e pela Análise do Discurso. Não se sugere que os conceitos sejam diretamente transferíveis para a sala de aula, é claro; mas defende-se que o professor deve alicerçar sua formação nos estudos empreendidos por esses ramos do saber humano. A Análise do Discurso e a Linguística Textual oferecem conhecimentos preciosos na base dos quais o professor pode não só desenvolver trabalhos de leitura mais satisfatórios em sala de aula, potencializando, assim, a capacidade de leitura de seus alunos, como também desenvolver sua própria capacidade de interpretação e compreensão do texto; afinal, como ensina o professor Paulo Coimbra Guedes (2006), as aulas de leitura devem ser ministradas por um leitor para leitores.

\section{REFERÊNCIAS}

Alves, R. (2002). As mãos perguntam, a cabeça pensa (artigo), publicado na Folha de São Paulo, em 21 de julho.

Brandão, H.H. N. (2004). Introdução à análise do discurso. Campinas, SP: Editora da Unicamp.

Guedes, P. C. (2006). A formação do professor de português - que língua vamos ensinar?. São Paulo: Parábola Editorial.

Koch, I. G. V. (2004). Introdução à Linguística Textual. São Paulo: Martins Fontes.

(2006). Desvendando os segredos do texto. São Paulo: Cortez

(2004). Argumentação e Linguagem. São Paulo: Cortez.

Liberato, Y. \& Lúcia F. (2007). É possível facilitar a leitura - um guia para escrever claro. São Paulo: Contexto.

Orlandi, E. P. (2008). Discurso \& Leitura. São Paulo: Cortez,. 


\section{O AUTOR}

Bruno de Andrade Rodrigues é professor do curso de Letras da Faculdade Paraíso. Mestre em Letras e especialista em português como língua estrangeira, atualmente, bolsista do $\mathrm{CNPq}$, é doutorando do curso de Estudos da Linguagem da Pontifícia Universidade Católica do Rio de Janeiro, instituição onde auferiu os dois referidos títulos.

E-mail: brunoletras@bol.com.br.

\section{ANEXOS}

\section{AS MÃOS PERGUNTAM, A CABEÇA PENSA}

Encaro com a maior desconfiança os laboratórios nas escolas. Acho que sua função, nas escolas, não é ensinar ciência aos estudantes, mas impressionar os pais. Os pais se impressionam facilmente. Vendo os laboratórios, eles concluem: "Uma escola com um laboratório moderno assim deve ser uma boa escola...".

Poucos se dão conta de que os laboratórios mentem aos adolescentes. Pois o que eles dizem, silenciosamente, é o seguinte: "É aqui dentro que se faz ciência". Isto é mentira. Ciência se faz em qualquer lugar. Ela só precisa de duas coisas: olho e cabeça. Assim, a primeira tarefa da educação científica é ensinar a ver e ensinar a pensar.

Sei de pessoas que são capazes de produzir pesquisas nos laboratórios, mas que, andando em meio aos objetos e situações de seu cotidiano, vêem e pensam como se nada soubessem da ciência. De fato, não sabem, porque a sua ciência só aconteceu em laboratórios.

Vocês se lembram do que escrevi sobre os moluscos, que, para sobreviver, constroem conchas eficazes e belas? E se lembram também que Piaget, começando a partir do fascínio pelos moluscos, concluiu que os seres humanos se comportam da mesma forma? Parece haver uma estratégia universal de sobrevivência, que une todos os seres vivos. Também nós, para sobreviver, construímos conchas eficazes e belas, conchas que são feitas com instrumentos e pensamentos. Pensamos para transformar o ambiente que nos cerca em conchas.

Nossas conchas se chamam casas. Casas não são apenas os pequenos espaços construídos com tijolo e cimento, onde moramos. Casas são os espaços habitáveis que nos cercam e onde a nossa vida acontece. Piaget sugere que o impulso para conhecer é o impulso para incorporar o espaço que nos rodeia. "In-corporado" quer dizer, colocar dentro do corpo. Ou seja, comer.

Queremos transformar a natureza em corpo. Quando isso acontece, o corpo fica grande, expande-se até os confins do universo... A natureza deixa de ser estranha, exterior. Passa a ser "casa", espaço habitável. Ou, se quiserem, a natureza humanizada, ou transformada em horta, boa para comer, ou em jardim, boa de gozar (...).

Pensei, então, numa escola que fosse uma casa, uma casa comum, dessas onde os alunos moram, parecida com o espaço de sua vida real. Essa idéia me veio quando uma amiga, professora universitária, me contou um incidente divertido e revelador.

Repentinamente, metade de sua casa ficou às escuras. Lembrou-se de que, quando algo semelhante acontecia na casa de sua infância, seu pai trocava os fusíveis. A professora concluiu, então, algum fusível devia ter queimado. Disse, pois, ao filho de 
nove anos: "Filho, veja se um fusível queimou". Respondeu o menino: "Não se usam mais fusíveis. Agora se usam disjuntores".

Mas ela não sabia o que eram disjuntores nem como estava estruturada a rede elétrica de sua casa, e assim continuou a conversa entre os dois, ela, professora universitária, que, para passar no vestibular, tivera de estudar física elétrica com suas voltagens, "wattagens", impedâncias, ohms, tensões, fórmulas e outras coisas parecidas, totalmente ignorante diante de um simples problema prático em sua casa; e o menino, que nunca estudara física, mas que conhecia os segredos da casa onde morava.

Embora isso esteja esquecido, o caminho para a inteligência passa pelas mãos. Pensamos para ajudar as mãos. Das mãos nascem as perguntas. Da cabeça nascem as respostas. Se a mão não pergunta, a cabeça não pensa. Pois o laboratório vem de "labore", trabalhar com as mãos, que é essa cooperação entre mãos, que é essa cooperação entre mãos e inteligência. Física mecânica, física elétrica, física hidráulica, física ótica, física de matérias, matemática, química, biologia, saúde, geografia, história, literatura, poesia, ecologia, política, sociologia, arte - todas moram na nossa casa, ferramentas e brinquedos, ao alcance das nossas mãos, desafios ao pensamento: conhecer para "laborare" na construção da casa de morada...

Li uma entrevista do Amyr Klink em que, indagado sobre a educação dos filhos, disse que gostaria que seus filhos aprendessem como aprendem as crianças numa ilha, se não me engano, na costa de Noruega: aprendem as coisas que devem ser aprendidas, para não ser nunca esquecidas (...) Assim, estamos de acordo...

Rubem Alves (psicanalista e escritor - professor da Unicamp) 